\title{
Histological assessment of the effect of neoadjuvant chemotherapy on conventional high grade osteosarcoma of the long bones
}

\author{
Thapa JB ${ }^{1}$
}

${ }^{1}$ Department of Pathology, Himal Hospital Pvt. Ltd., Kathmandu, Nepal

\author{
Keywords: \\ Neoadjuvant \\ chemotherapy; \\ Osteosarcoma; \\ Total histological mapping; \\ Tumour response
}

\begin{abstract}
A multidisciplinary team of an orthopaedic surgeon, medical oncologist, radiologist and pathologist was involved in the management of osteosarcoma cases. Four cases of osteosarcoma were examined for the effects of neoadjuvant chemotherapy. Total histological mapping was done to study the postchemotherapy biopsies. Two cases were good responders (more than $90 \%$ response), and two cases were poor responders (less than $90 \%$ response). Good responders had limb sparing surgery performed on them. Long term follow up results are awaited.
\end{abstract}

\section{INTRODUCTION}

Osteosarcoma often presents as a high grade aggressive bony neoplasm affecting mostly the young and sometimes the elderly. Adoption of a robust multi-specialty and multimodality therapeutic strategy worldwide has made significant strides in the management of this neoplasm. Though most of the medical manpower are often scattered working in the different institutions in Kathmandu, we too have started to use a team of an orthopedic surgeon, medical oncologist, radiologist and pathologist for the diagnosis and management of the tumour using neoadjuvant chemotherapy followed by surgery, often limb sparing. This study was done to study the effect of chemotherapy on the tumour mass.

\section{CASE SERIES}

Four osteosarcoma cases were referred in the last year from Capital Hospital for pre and post neoadjuvant chemotherapy

\footnotetext{
Correspondence:

Dr. Jung B. Thapa

Department of Pathology, Himal Hospital Pvt. Ltd., Kathmandu, Nepal

Email: jungbahadurthapa@gmail.com
}

tumour response histological study. Biopsy specimens along with the relevant clinical information and imaging films were used. The subjects were biopsy confirmed osteosarcoma patients who were to undergo neoadjuvant chemotherapy at Capital Hospital. Patients were committed to long term care and follow up at that hospital. Two biopsies were used in each case to study the response of the sarcoma to the chemotherapy. The first biopsy was initially done as a diagnostic biopsy, and consisted of either an incisional biopsy or wide bore needle biopsy. This was followed by a set of chemotherapy administered before to the surgery. A second biopsy was then done with wide excision of the bone involved. This was subjected to total histological mapping in the laboratory to study the effect of chemotherapy on the tumour cells as per Huvos et al - Memorial Sloan-Kettering Cancer Center, ${ }^{1}$ Salzer-Kuntschik et al - German-AustrianSwiss Cooperative Osteosarcoma Study Group (COSS), ${ }^{2}$ Picci et $\mathrm{al}^{2}$ - Instituti Ortopedico Rizzoli (IOR) in Bologna. (fig. 1 $)^{3}$ In this study the more widely accepted criteria i.e. more $90 \%$ necrosis as a good responder and $<90 \%$ necrosis as a poor responder was used to separate the good responders from the poor responders (fig. 2). 


\section{TOTAL HISTOLOGICAL MAPPING}

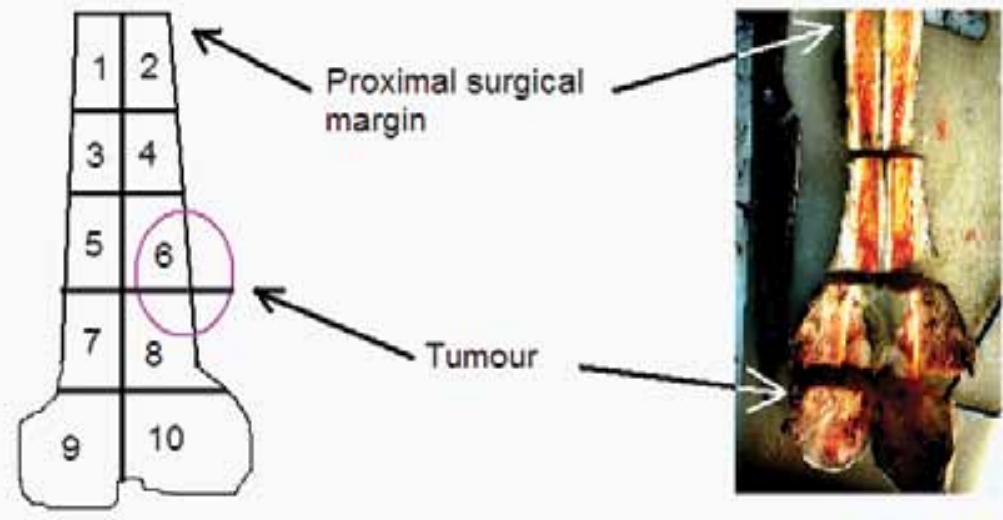

Figure 1: Total Histological Mapping Procedure

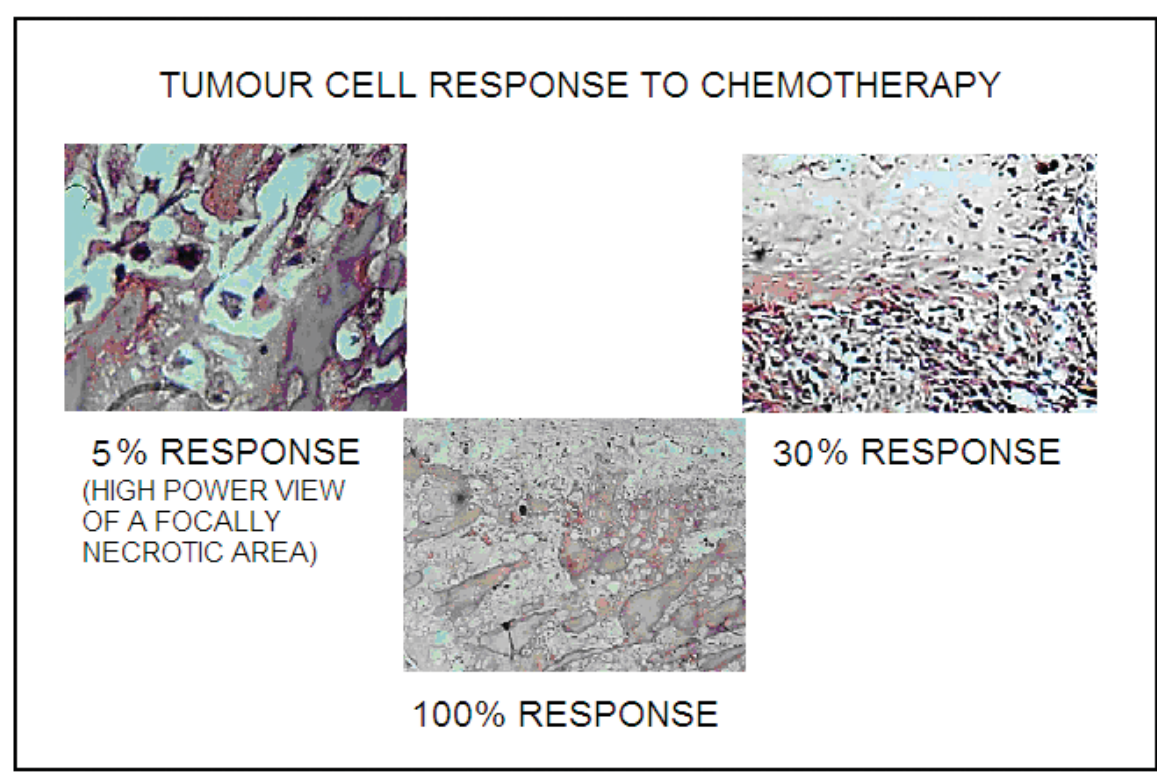

Figure 2: Tumour Cell Response to the Chemotherapy

\section{RESULTS}

Four patients were studied for response to neoadjuvant chemotherapy. They included three males and one female. The age group ranged from 12 to 19 years. All of the cases were high grade central conventional type and located in the distal femur. Three cases were of the osteoblastic variant and one was the chondroblastic variants. Two cases showed good response and two cases showed poor response (Table $1)$.

Although the number of patients is very limited, half of them were good responders. Low power scanning of the histology section was done to assess the effect of chemotherapy on the tumour cells. Necrotic areas showed non-viable cellular debris, residual osteoid and bony trabeculae and scanty inflammatory cells, (fig. 2).

\section{DISCUSSION}

Most cases of osteosarcoma are now assumed to be systemic diseases on presentation even though no pulmonary secondaries are visualized by conventional or advanced imaging techniques like bone scans, spiral computed tomography (CT) scans, Thallium scintograms or magnetic resonance imaging (MRI). Rosen pioneered the use of neoadjuvant chemotherapy at the Memorial Sloan Kettering Hospital, New York. ${ }^{4}$ This treatment strategy was developed almost accidentally as patients had to wait for a few months for surgery as their prosthesis were being custom made, and it was decided to offer them a course of preoperative chemotherapy to shrink their tumour mass. Prior to neoadjuvant chemotherapy surgery used alone had resulted in only 15 $20 \%$ long term survival rates. There was recurrent pulmonary disease in $50 \%$ of the cases within 6 months. This led Marina to raise the view that osteosarcoma shows micro metastases even with localized disease in the absence of any pulmonary disease detected by imaging modalities. ${ }^{5}$ This has resulted in the use of systemic neoadjuvant chemotherapy to attack the microfoci of neoplasm followed by surgery. Surgical resection was preferred to radiation as osteosarcoma is generally not radiosensitive. The response to chemotherapy is currently the most sensitive indicator of long survival. Different authors have used different scales of grading. The different histological criteria that have been used by different authors to study the response of the sarcoma cells to the chemotherapy in various other centers are listed in Table 2.

Grading of the response is also prone to inter-observer variation errors. The time of surgery after chemotherapy can also affect the histological response. Current regimens

Table 1: Case results details

\begin{tabular}{cccccc}
\hline $\begin{array}{l}\text { Case } \\
\text { No. }\end{array}$ & Sex & Age & Variants * & \% Necrosis & Inference \\
\hline 1 & M & 15 & OB & 5 & Poor \\
2 & F & 12 & CB & 100 & Good \\
3 & M & 17 & OB & 30 & Poor \\
4 & M & 19 & OB & 100 & Good \\
\hline
\end{tabular}

*OB $=$ osteoblastoma, $C B=$ chondroblastoma 
Table 2: Different Histological Grading Systems for Response to Neoadjuvant Chemotherapy for Osteosarcoma

\begin{tabular}{lllll}
\hline Huvos & $\begin{array}{l}\text { IV No tumour } \\
\text { cells seen }\end{array}$ & $\begin{array}{l}\text { III Scattered foci of } \\
\text { tumour cells seen }\end{array}$ & $\begin{array}{l}\text { II Areas of necrosis } \\
\text { and tumour cells seen. }\end{array}$ & $\begin{array}{l}\text { I Little or no tumour } \\
\text { response seen }\end{array}$ \\
$\begin{array}{llll}\text { Salzer-Kunts- } \\
\text { chik }\end{array}$ & $\begin{array}{l}\text { I No viable } \\
\text { tumour cells }\end{array}$ & $\begin{array}{l}\text { II Single tumour cells } \\
\text { or clusters }<0.5 \mathrm{~cm}\end{array}$ & $\begin{array}{l}\text { III Viable tumour } \\
\text { cells }<10 \% \text { seen }\end{array}$ & $\begin{array}{l}\text { IV Viable tumour } \\
\text { cells } 10-50 \% \text { seen }\end{array}$ \\
\hline Picci & $\begin{array}{l}\text { Total tumor } \\
\text { response }\end{array}$ & Good tumour response & Fair tumour response & Poor tumour response \\
\hline
\end{tabular}

use $10-12$ weeks of chemotherapy preoperatively. It is now widely accepted that $>90 \%$ necrosis is good response and $<90 \%$ response is poor response. ${ }^{6-8}$ Good responders to neoadjuvant chemotherapy show $80-90 \%$ long term survival (more than 10 years). Poor responders show only $15 \%$ long term survival. The use of multidisciplinary and multimodality therapy has resulted in disease free survival of $60-80 \%$. Functional limb sparing surgery can be used in more than $80 \%$ of patients. Bacci et al report a $60 \%$ good response to neoadjuvant chemotherapy with good response seen especially in the fibroblastic and telangiectic variants. Chondroblastic variant showed poor long term survival. ${ }^{9}$ Our single chondroblastic variant showed good initial response to the chemotherapy. Long term follow up is yet to be studied. This case study reveals a $50 \%$ good response rate, and these patients were treated by limb sparing surgery. Both good function and long term survival is anticipated in these cases.

\section{CONCLUSION}

From this study it is expected that more bone sarcomas will be managed by limb sparing surgery in Nepal in the future.

\section{ACKNOWLEDGMENT}

I wish to express deep regards to the other prestigious members of the team, Prof. Dr. Ashok Bajracharya, Orthopedic Surgeon, Dr. Sudeep Shrestha, Medical Oncologist and Dr. Ram Kumar Ghimire, Consultant Radiologist.

\section{REFERENCES}

1. Huvos AG, Rosen G Marcove RC. Primary osteogenic sarcoma; pathologic aspects in 20 patients after treatment with chemotherapy en bloc resection, and prosthetic bone replacement. Arch Pathol Lab Med 1977;101:14-8.

2. Salzer-Kuntschik M, Delling G, Beron G, Sigmund R. Morphological grades of regression in osteosarcoma after polychemotherapy study COSS 80, J Cancer Res Clin Oncol 1983;106:21-4.

3. Picci P, Bacci G, Campanacci M et. al. Histological evaluation of necrosis in osteosarcoma induced by chemotherapy. Regional mapping of viable and nonviable tumour. Cancer 1985;56:1515-21.

4. Rosen G, Marcove RC, Caparros B, Nirenberg A, Kosloff C, Huvos AG. Primary osteosarcoma: The rational for preoperative chemotherapy and delayed surgery. Cancer 1979;43:2163-77.

5. Marina N, Gebhardt M, Teot L, Gorlick R. Biology and therapeutic advances for pediatric osteosarcoma. Oncologist 2004;9:422-41.

6. Roland TS. Handbook of Cancer Chemotherapy, 7 ed. Lippincott Williams \& Wilkins; 2007.

7. Kantarjian HM, Wolf RA, Koller CA. The MD Anderson Manual of Medical Oncology, McGraw Hill Access Medicine; 2005.

8. Inbach P, Kuhne T, Pediatric Oncology. Springler Verlag; 2004.

9. Bacci G, Bertoni F, Longhi A. et al: Neoadjuvant chemotherapy for high grade central osteosarcoma of the extremity. Histologic response to preoperative chemotherapy correlates with histologic subtype of the tumour, Cancer 2003;97: 3068-75. 